\title{
EXTENSÃO UNIVERSITÁRIA: UMA ANÁLISE DA CONSTRUCÃO DE UM PROJETO DE EXTENSÄO COM AS MULHERES RURĂIS DO BAIRRO PEROBA DE ITAJUBÁ - MG
}

\author{
UNIVERSITY EXTENSION: AN ANALYSIS OF THE \\ CONSTRUCTION OF AN EXTENSION PROJECT WITH THE \\ PEROBAS' NEIGHBORHOOD RURAL WOMEN OF ITAJUBA - MG
}

Tayrine Parreira Brito* Samanta Borges Pereira** Ednilson Moisés de Lima e Silva***

Gabriela Santos**** Pamela Hélia de Oliveira***** Viviane Guimarães Pereira****** Vitor Monteiro de Andrade******* Kalahan de Mello Battiston******** Miguel de Souza Pereira*********

Resumo: A extensão universitária é o instrumento mantenedor do diálogo da Universidade com a sociedade. A Política Nacional de Extensão Universitária (PNEU) fornece direcionamentos, nos quais os projetos de extensão devem se fundamentar e guiar suas ações. Partindo desse princípio, o objetivo deste trabalho é analisar os caminhos percorridos pelo Núcleo Travessia na execução do projeto de extensão "Economia Solidária na Peroba Itajubá-MG: geração de renda e emancipação social das mulheres rurais". Para a análise, foram realizadas comparações entre os procedimentos adotados pelo Núcleo Travessia e as diretrizes descritas na PNEU. Os resultados apontaram para a importância da Interação Dialógica desde a aproximação com a comunidade e sua relevância no estabelecimento da relação de respeito e confiança. A melhoria na autoestima e a conquista dos primeiros rendimentos mostraram o potencial de Transformação Social em projetos dessa dimensão, fazendo com que a Universidade cumpra com a sua missão de fomento ao desenvolvimento social.

Palavras chave: Dialogicidade; Política Nacional de Extensão Universitária; Economia Solidária; Agricultura Familiar.

\begin{abstract}
Outreach university projects are tools to maintain the dialogue between the university and society. The National Policy for Outreach Projects (PNEU in the Portuguese acronym) provides guidelines to support and inform outreach actions. Based on this principle, the aim of this study is to analyze the steps taken by the Núcleo Travessia in the implementation of the outreach project called Solidarity Economy in Peroba - Itajubá - MG: income generation and social emancipation of rural women". The analysis compared the procedures adopted by the Núcleo Travessia to the procedures described in the PNEU. The results pointed out the importance of Dialogic Interaction from its closeness to the community and its relevance in the establishment of a relationship of respect and confidence. The improvement of self-esteem and the achievement of the first incomes showed the potential of Social Transformation of projects like this that allow the university to fulfill its mission of fostering social development.
\end{abstract}

Keywords: Dialogicity; National Policy of University Extension; Solidarity economy; Family farming.

*Aluna de Mestrado da Universidade Federal de Itajubá (UNIFEI), Itajubá - MG, Brasil. E-mail: tairine_prospe@hotmail.com **Aluna de Doutorado da Universidade Federal de Lavras (UFLA), Lavras - RS, Brasil. E-mail: samantaborges81@gmail.com ***Aluno de Mestrado da Universidade Federal de Itajubá (UNIFEI), Itajubá - MG, Brasil. E-mail: ednilsonmlima7@gmail.com ****Aluna de Mestrado da Universidade Federal de Itajubá (UNIFEI), Itajubá - MG, E-mail: santos-gabriela@live.com

*****Aluna de Mestrado da Universidade Federal de Itajubá (UNIFEI), Itajubá - MG, Brasil. E-mail: pamela.oliveira@ifsuldeminas.edu.br ******Professora da Universidade Federal de Itajubá (UNIFEI), Itajubá - MG, Brasil. E-mail: vgpereira@yahoo.com.br *******Aluno de Graduação da Universidade Federal de Itajubá (UNIFEI), Itajubá - MG, Brasil. E-mail: vmonteiro.andrade@gmail.com ********Aluno de Graduação da Universidade Federal de Itajubá (UNIFEI), Itajubá - MG, Brasil. E-mail: kalahanmb@gmail.com ********Aluno de Graduação da Universidade Federal de Itajubá (UNIFEI), Itajubá - MG, Brasil. E-mail: miguelpereira369@gmail.com 


\section{Introdução}

O diálogo entre Universidade e sociedade é recurso vital para que a instituição pública de ensino superior cumpra com sua missão de fomentar o desenvolvimento local e, nesse sentido, os projetos de extensão são importantes propulsores desse diálogo, visando a construção conjunta de aprendizagem e emancipação social. O Núcleo Travessia ${ }^{1}$ vem atuando nesse sentido e desde o final de 2016, vem se aproximando da comunidade da Peroba, bairro rural do município de Itajubá (MG), distante 15 quilômetros da sede municipal. A partir dos resultados parciais de projeto de pesquisa, o grupo de mulheres do bairro apresentou demandas que envolviam capacitação para atividades que as valorizassem enquanto agricultoras e alavancassem processos de geração de renda.

Em 2017, o Núcleo Travessia aprovou o projeto de extensão "Economia Solidária na Peroba - ItajubáMG: geração de renda e emancipação social das mulheres rurais", com o propósito de promover a sensibilização da comunidade para a economia solidária, bem como a capacitação do grupo de mulheres na utilização de técnicas de processamento e beneficiamento de frutas, legumes e verduras que possibilitassem a geração de renda, tornando-se uma possibilidade de emancipação econômica e social.

Para executar o projeto, foi importante compreender que a extensão universitária deve ser um processo contínuo de comunicação entre a Universidade e a sociedade, ultrapassando os preceitos assistencialistas e sendo capaz de transformar a realidade onde se aplica. Cada grupo social possui uma realidade distinta, demandando diferentes caminhos de modo a adequá-los às diferentes realidades.

A avaliação dos percursos adotados pelos grupos que se propõem desenvolver projetos de extensão é fundamental para o aprimoramento da metodologia de trabalho em extensão, podendo contribuir com outros grupos extensionistas. O objetivo deste artigo foi discutir os caminhos percorridos pelo Núcleo Travessia na construção e execução do projeto de capacitação realizado junto às mulheres do bairro Peroba, em Itajubá (MG). Trata-se de avaliação das decisões e direcionamentos tomados pelo Núcleo Travessia na execução do projeto.

Para isso, foram analisadas as seguintes etapas do projeto: 1) o diagnóstico e levantamento das demandas junto à comunidade; 2) as oficinas de capacitação das mulheres; 3) os espaços para formação coletiva e solidária. Para a análise foram verificadas se as ações do Núcleo Travessia estiveram emparelhadas com as diretrizes da Política Nacional de Extensão Universitária (PNEU) e condizente com a teoria que orienta à extensão universitária.

De acordo com a política nacional, a extensão universitária é o processo acadêmico que permite a existência de uma relação transformadora entre a Universidade e a sociedade. Para tanto, foram descritas as seguintes diretrizes para as ações de extensão universitária: Interação Dialógica, Interdisciplinaridade e Interprofissionalidade, Indissociabilidade EnsinoPesquisa-Extensão, Impacto na Formação do Estudante e Impacto e Transformação Social (FORPROEX, 2012). O estreitamento dos caminhos do Núcleo Travessia com as diretrizes foi explicitado no texto e destacado em itálico, para facilitar a identificação do emparelhamento entre diretriz e prática.

O trabalho do grupo junto à comunidade ainda é recente e a aproximação com as lideranças locais e o estabelecimento da relação de confiança foram fundamentais para a realização de um projeto que atendesse à demanda da comunidade, a partir de suas habilidades e de seus recursos. A reflexão sobre o percurso desenhado pelo Núcleo Travessia para o desenvolvimento desse projeto permitirá identificar as necessidades de ajustes na continuação do trabalho junto às mulheres da Peroba e com a comunidade como um todo.

\section{Diretrizes para as ações de extensão}

No processo histórico das Universidades brasileiras, o conceito de extensão universitária passou por diversos princípios conceituais. Por meio de uma breve análise histórica, se encontra pelo menos quatro pontos significativos para a sua conceituação: (1) extensão enquanto cursos de treinamento via transmissão vertical do conhecimento; (2) extensão do serviço na forma de voluntariado; (3) extensão como ação sócio comunitária institucional, por meio do assistencialismo; (4) extensão na forma de reconfiguração da educação superior, enquanto prestação de serviço para a arrecadação financeira à Instituição (FREIRE, 2011).

Os Pró-Reitores de extensão das universidades públicas brasileiras elaboraram um documento com o compromisso de que este fosse um instrumento colaborativo para a mudança social em direção à justiça, à solidariedade e à democracia, trabalho intitulado de Política Nacional de Extensão Universitária (PNEU). Essa política foi construída com a ampla participação dos Pró-Reitores de Extensão e de representações das Universidades Públicas signatárias, sendo a primeira versão aprovada em maio de 2012 (FORPROEX, 2012).

Assim, buscou-se apresentar quais foram os caminhos percorridos pela extensão no contexto brasileiro e internacional, bem como, quais foram as implicações que a extensão alcançou no cenário das políticas públicas nacionais e das Universidades brasileiras. Reuniu-se princípios que determinaram que as ações de extensão devem retornar em transformações sociais, pautadas na interação dialógica, na interdisciplinaridade e na indissociabilidade entre o ensino, pesquisa e extensão, além de causar impacto na formação do estudante (FORPROEX, 2012). 
Paulo Freire (2006) discutiu e criticou a extensão sob o ponto de vista do processo "verticalizado", no qual a atuação ocorre de forma autoritária por parte da Universidade. Essa, por meio de suas atividades extensionistas, apresenta-se como a detentora do saber absoluto, de forma superior e redentora da ignorância. Freire apontou que uma atividade extensionista necessita de proponentes que tenham o conhecimento da cultura a quem se destina a sua prática e, portanto, estabeleçam uma interação dialógica, onde todos os envolvidos sejam sujeitos que atuem e pensem criticamente (FREIRE, 2006). Pautado na teoria de Paulo Freire e sob as diretrizes apresentadas pelo FORPROEX, o Núcleo Travessia procurou desenvolver o trabalho junto às mulheres da Peroba. Com esses parâmetros, analisaremos os caminhos percorridos pelo grupo na execução do projeto.

\section{Caracterização da comunidade da Peroba}

A Peroba está localizada na Serra da Mantiqueira e é cercada pela Mata Atlântica, como pode ser visto na Figura 01. A partir das observações e visitas realizadas na comunidade, foi possível perceber (pelo desenho geológico de localização do bairro) que a região possui água em abundância, com inúmeras nascentes que brotam entre as serras, onde há forte presença de produção agropecuária, predominantemente, familiar.

Figura 1: Localização do bairro Peroba dentro do município de Itajubá-MG.

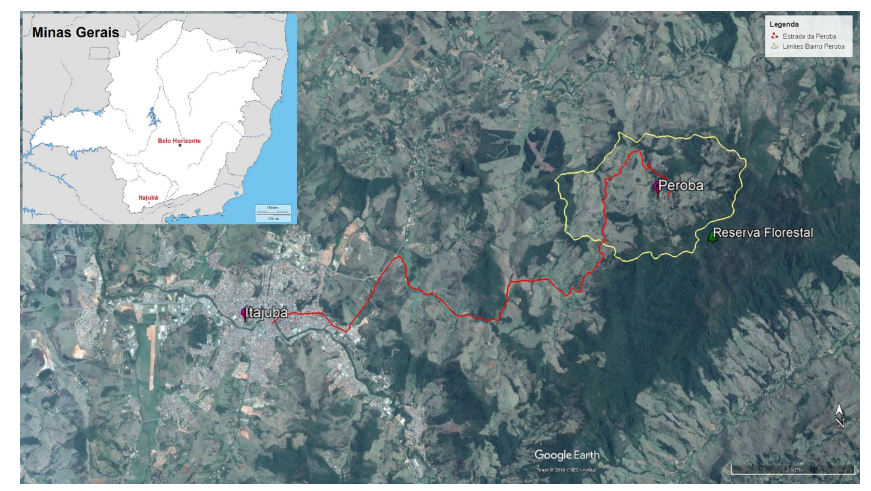

Fonte: Imagens de satélite do Google Earth/ elaborado pelos autores.

Economicamente, as famílias moradoras do bairro vivem da comercialização dos produtos dessas atividades e de produtos do artesanato, com destaque para a produção orgânica e participação em feiras locais. Composto por aproximadamente 100 moradores, o bairro apresenta características de uma comunidade parentesca, compartilhando um conjunto de memórias do passado, com fortes laços de união, solidariedade e religiosidade. Em diálogo estabelecido com as famílias, foi relatado que todas as casas do bairro possuem energia elétrica e, a maior parte dos moradores, tem acesso à internet e serviços de telefonia celular, embora a rede convencional de celular funcione somente em determinados pontos.
Registrou-se, por meio de conversas com o grupo feminino da comunidade, que as mulheres adultas, em sua maioria, são casadas. Algumas trabalham na cidade, outras no próprio bairro com a produção artesanal de queijos e quitandas, outras estão aposentadas. As jovens estudam nas faculdades e nas escolas municipais e estaduais da cidade.

A aproximação com a comunidade e a identificação das necessidades das mulheres, que se desencadearam no projeto de extensão, serão apresentados nas seções seguintes.

\section{Aproximação com a comunidade e levantamento de demandas}

A chegada em uma comunidade rural carece de procedimentos sutis, já que palavras ou ações mal colocadas podem dificultar a relação de confiança, diálogo e troca. De acordo com Zuin, Zuin e Manrique (2011, p. 13), "somente por meio de uma relação de parceria orientada por diálogos entre os pares é que são construídas as relações de confiança". Para construir esse tipo de relação é preciso pisar no mesmo chão, comer da mesma comida, falar a mesma língua, cantar o mesmo canto. Cientes dessa necessidade, a aproximação do Núcleo Travessia aconteceu, inicialmente, de maneira informal.

No encontro sobre Alimentação Escolar e Mercados Institucionais, realizado em 2016, a coordenadora do Núcleo Travessia conheceu um agricultor do bairro da Peroba. A conversa limitou-se à necessidade pessoal da coordenadora em adquirir um determinado produto oriundo da comunidade. Semanalmente, agricultor e, agora, consumidora se encontravam na Feira Agroecológica e Cultural de Itajubá (FACI) para efetuar a relação de compra e venda e conversarem sobre suas experiências, num processo de interação dialógica, interdisciplinar e interprofissional.

$\mathrm{O}$ agricultor, liderança comunitária, dividia as conquistas e os desafios enfrentados pela agricultura familiar, principalmente quanto à produção $\mathrm{e}$ comercialização. A consumidora compartilhava sua experiência em desenvolvimento de comunidades rurais e as dificuldades dentro da Universidade sobre esse tema, principalmente quanto à formação dos estudantes que, apesar do interesse de muitos em se importarem mais com as questões sociais, ficam distanciados das realidades da sociedade, além da ausência de recurso financeiro destinado às atividades extensionistas, inconvenientes que dificultam a efetivação da indissociabilidade ensino-pesquisaextensão.

Dessa relação surgiu o interesse tanto do agricultor quanto da coordenadora de aproximar Universidade e Comunidade. As trocas iniciais que ocorreram na feira - reconhecidamente um lugar social 
de trocas materiais e imateriais (sociais, históricas e culturais) (PEREIRA; BRITO; PEREIRA, 2017) permitiram a aproximação desses grupos (Núcleo Travessia e bairro da Peroba), abrindo oportunidade para a efetivação do diálogo Universidade e sociedade ${ }^{2}$.

A primeira visita à Peroba ocorreu no dia 07 de outubro de 2016 e envolveu a visitação em 03 famílias agricultoras. A partir dos diálogos estabelecidos com os agricultores e agricultoras em suas propriedades, foram levantadas informações sobre os cultivos existentes (hortas, pomares, lavouras, entre outros), produção animal (suínos, aves, bovinos, etc.), produtos beneficiados, processados e as formas de comercialização da produção. $\mathrm{O}$ encontro contou com a presença de um agricultor de Conceição do Mato Dentro e uma agricultora de Dom Joaquim, municípios localizados na Serra do Espinhaço, região próxima ao Vale do Jequitinhonha, fazendo cumprir a Interdisciplinaridade e Interprofissionalidade indicada no PNEU. A junção entre os agricultores e agricultoras possibilitou trocas de experiências sobre a agricultura familiar em realidades distintas.

A segunda visita aconteceu no dia 11 de dezembro de 2016, e envolveu a participação de toda a comunidade. Essa etapa pretendeu diagnosticar as demandas de produção e comercialização. Para isso, foram utilizados elementos da Metodologia Participativa, fundamental na execução de projetos de extensão, de modo que o mesmo pudesse ser construído de maneira coletiva. Segundo Morais e Callou (2017, p. 09),

\section{[...] as metodologias participativas devem ser vistas como um fator positivo, pois, ao possibilitar o contato direto dos assessores com os agricultores, permite conhecer seus desejos, criar vínculos e respeito que vão além de uma simples assessoria. Ou seja, possibilitam confiança na coletividade e credibilidade em si próprio.}

O encontro contou com a presença de 25 moradores da Peroba que foram divididos em três grupos: homens, mulheres e jovens. Cada grupo foi mediado por dois membros do Núcleo Travessia, com o apoio de um mediador externo. Esse encontro abarcou as cinco diretrizes do PNEU. Para sua execução e efetivação, contou-se com a Interação dialógica entre os grupos, quando do levantamento das demandas da comunidade. A Interdisciplinaridade e Interprofissionalidade e o Impacto na Formação dos Estudantes ficaram por conta das formações dos diversos membros do Núcleo Travessia - Economia, Engenharia Mecânica, Administração, Gestão Ambiental, Engenharia Ambiental, Engenharia Hídrica, História, Direito - do mediador externo experiente em educação popular e metodologias participativas, e da experiência de vida e trabalho da comunidade, intrínseca à realidade do ambiente rural.

A diversidade de formações disciplinares, juntamente à sensibilidade do grupo, levou à organização desse espaço e definição de metodologia que permitisse o contato com uma das grandes questões do nosso país - o Desenvolvimento Rural -, o diálogo com a comunidade e o registro das informações de modo a possibilitar a visualização de direcionamentos futuros para a comunidade, reafirmando e materializando o compromisso ético e solidário da Universidade pública brasileira e a formação cidadã dos docentes e discentes que a compõem (FORPROEX, 2012).

Os grupos discutiram e registraram as potencialidades, dificuldades e as expectativas quanto à presença do Núcleo Travessia junto à comunidade, mostrando a indissociabilidade ensino-pesquisaextensão, emergindo um novo espaço de participação e apreensão de conhecimento (FORPROEX, 2012). Após a discussão grupal, as percepções foram apresentadas coletivamente, conforme sintetização apresentada no quadro 01 .

Quadro 1: Categorização das potencialidades, dificuldades e expectativas da comunidade

\begin{tabular}{|l|l|l|}
\hline Potencialidades & Dificuldades & Expectativas \\
\hline Religiosidade & Saúde & Apoio na produção familiar \\
\hline Laços familiares & Estradas & Apoio na comercialização \\
\hline Natureza & Transporte & Geração de renda \\
\hline Segurança & Lazer/entretenimento & Lazer \\
\hline Produção tradicional & Capacitação & Intermediário campo/cidade \\
\hline & Comercialização & \\
\hline
\end{tabular}

Fonte: LIMA et al. (2018).

Além do apoio na produção e comercialização, vale salientar que a expectativa de geração de renda, capacitação e entretenimento para as mulheres foram umas das questões mais abordadas pelos grupos, até mesmo pelos homens, que colocaram como prioridade.

No entanto, essa atenção às mulheres levanta duas reflexões: (1) a demanda das mulheres rurais é algo legítimo e vem sendo discutido entre os princípios do desenvolvimento rural de base territorial; (2) a invisibilidade do trabalho feminino no meio rural. Para compreender a luta das mulheres do campo, é essencial perceber que no contexto familiar-rural-camponesa, relações de gênero injustas ainda são replicadas, reforçando o poder patriarcal (FERREIRA; MATTOS, 2017). Esse modelo de sociedade patriarcal foi estabelecendo papeis e funções específicos para homens e mulheres, valorizando mais as funções ditas masculinas e dissimulando o papel das mulheres, levando-as a acreditar que não tinham importância no desenvolvimento de seu grupo social (SARAIVA, 2012).

Segundo os dados do Censo Agropecuário de 2006, um terço das ocupações na agricultura familiar são preenchidas por mulheres, o que representa 4,1 milhões de trabalhadoras (IBGE, 2006). A mão de obra feminina está presente há tempos nas atividades da agricultura, porém a sua identidade é ocultada pelo trabalho desenvolvido no contexto familiar, ou seja, pela atuação dos homens, mulheres, filhos e idosos (HEREDIA, 1979; GARCIA JR., 1993). De acordo 
com Pacheco (1996), ocorre uma forte depreciação pelas fontes estatísticas oficiais quanto ao trabalho produtivo realizado pelas mulheres na seara da agricultura familiar. A visão que se atribui sobre a função que a mulher do campo assume na propriedade rural está ligada à ocupação do espaço da casa e de que a sua principal tarefa é com as atividades domésticas. Assumindo esse papel, sua invisibilidade ocorre porque essa perspectiva está fortemente relacionada à percepção de que tais atividades não são expressas em valores financeiros e tão pouco evidenciadas pela sociedade.

Ainda que a igualdade de gênero e a violência contra a mulher camponesa ainda não tenham sido suplantadas, as organizações têm conquistado espaço em programas que valorizam as experiências dessas mulheres. Estudando a comunidade Rancharia, em Campo Alegre de Goiás (GO), Mesquita e Mendes (2012) observaram que a família agrícola acredita que a mulher atua na condição de "ajudante" do processo produtivo, visto que, ao contrário do homem, ela trabalha eventualmente e dedica poucas horas às tarefas ligadas ao setor, pois tem a incumbência dos afazeres domésticos. Porém, as autoras identificaram que, dentre as mulheres entrevistadas, $64 \%$ lidam com a ordenha, $36 \%$ com gado leiteiro e $27,3 \%$ com gado de corte, mostrando uma contradição sobre a atuação feminina nas atividades da propriedade rural.

Justifica-se assim, a atuação do Núcleo Travessia para atender à necessidade das mulheres rurais do bairro da Peroba, grupo social e historicamente excluído, na tentativa de contribuir com o impacto e a transformação social da vida dessas mulheres. Diante de tantas demandas, a luta feminista no ambiente rural também é uma forma de fortalecer a comunidade como um todo.

\section{Elaboração do projeto e capacitação nas técnicas de processamento}

Com a abertura do Edital PROEXT $2017^{3}$ para financiamento de projetos de extensão sociais e culturais da UNIFEI, o Núcleo Travessia submeteu uma proposta a fim de que fosse contemplada a demanda das mulheres da Peroba. A partir das necessidades apresentadas no segundo encontro na comunidade, o Núcleo Travessia reuniu-se novamente com as mulheres para delinear os caminhos do projeto, mantendo a interação dialógica com a comunidade. Para alinhar a proposta à linha temática "Empreendedorismo social e economia solidária", o eixo do projeto seria a capacitação das mulheres.

Para a definição de quais capacitações seriam as mais adequadas, os seguintes aspectos foram discutidos: a utilização da matéria prima disponível na comunidade ou em suas casas e a infraestrutura disponível. Esses aspectos foram colocados no sentido de incentivar os costumes locais e os alimentos nativos e de minimizar os desperdícios e as perdas de produtos perecíveis que se tornam impróprios para o consumo familiar e para a comercialização.

A proposta do projeto, construída conjuntamente com as mulheres do bairro rural da Peroba, foi capacitá-las para o processamento e beneficiamento de frutas e hortaliças, de modo que resultassem em doces, geleias, compotas e conservas. Além disso, pretendia-se fomentar a organização coletiva para formação de um grupo forte de produção, comercialização, geração de renda, trocas de experiências, solidariedade e emancipação. A execução do projeto na Peroba foi semelhante ao que ocorreu na Comunidade Vale do Sol II, em Tangará da Serra - MT, em parceria com o SENAR, onde as mulheres também se organizaram em um grupo produtivo de doces e conservas para aumentar a renda familiar (SOUZA et al., 2016). Outro exemplo semelhante são as mulheres do Assentamento Carnaúba dos Ajudantes que criaram o grupo Reciclarte depois de uma oficina de aproveitamento de materiais recicláveis oferecida pelo grupo UAST da Universidade Federal Rural do Pernambuco (MÉLO; MORAES; COSTA, 2014).

Conforme Ramos (2014, p. 13), “aos poucos se confirma o poder de articulação e implementação da mulher rural nos meios produtivos e reprodutivos da vida conjunta". Os grupos formados por mulheres rompem com o silêncio histórico no qual elas foram confinadas, proporcionando a socialização e a reflexão dos problemas vividos por elas, sendo essa participação vista como uma atuação política e social (BRUNO, 2013; MÉLO; MORAES; COSTA, 2014).

Após aprovação do projeto, o grupo se organizou para encontrar, na região, profissional capacitado para executar esse tipo de trabalho. Essa foi a primeira dificuldade do projeto: adequar o recurso disponibilizado ao profissional apropriado para capacitação junto às comunidades rurais. Os membros do Núcleo Travessia fizeram diversos esforços para levantar possibilidades de contato que pudessem oferecer ou indicar profissional para atender à necessidade do projeto. Foram encontrados cursos de formação em uso de técnicas de processamento de alimentos perecíveis, mas a proposta se voltava para a formação empresarial e competitiva. Ao procurar por agentes de desenvolvimento rural, os mesmos informaram não terem profissional disponível para esse tipo de trabalho.

Segundo Landini (2015), um dos maiores problemas da extensão rural brasileira é a perspectiva difusionista adotada por grande parte dos extensionistas, que vai na contramão da abordagem participativa e dialógica. Para o autor, esses extensionistas enxergam o problema sempre nos agricultores, se limitando à autocrítica do trabalho prestado. Há que se diferenciar a visão simplista de extensão rural enquanto assistência técnica e a visão mais ampla, enquanto processo educativo de comunicação de conhecimentos de diversas naturezas. 
A primeira visa resolver problemas pontuais, sem a preocupação de capacitação e troca de conhecimento (PEIXOTO, 2008). Isso ajuda a explicar a dificuldade em encontrar um profissional adequado.

Dentre as diversas possibilidades elencadas, o Núcleo Travessia conseguiu retorno de uma profissional experiente em desenvolver trabalhos com as mulheres da zona rural de Cristina, município vizinho. Além do conhecimento das técnicas de processamento e de higienização, a profissional conhecia a forma de diálogo necessária para estabelecer a confiança entre ela e as mulheres da comunidade.

A adequação orçamentária também aconteceu após negociação com a mesma, a qual abriu mão de parte dos seus ganhos para poder realizar esse trabalho, pois acreditava e compreendia a importância que essa formação representaria para aquelas mulheres. Essa escolha esteve alinhada à Interprofissionalidade indicada no PNEU. Ainda que alguns membros do Travessia conhecessem técnicas de processamento, havia as especificidades do grupo - mulheres rurais que precisavam ser atentamente observadas. A comunicação precisava estar alinhada à compreensão desse grupo, sem constrangimentos, incompreensões e/ou desconfortos.

$\mathrm{O}$ encontro de abertura das oficinas aconteceu com a participação da coordenadora do projeto, dois membros do Núcleo Travessia, a facilitadora contratada e as 10 mulheres da comunidade. Foi formada uma roda onde todas deram as mãos e falouse da relação de afeto já existente naquele grupo, ligado por laços sanguíneos, por relações que se seguem há muitas gerações. Para sensibilizar o grupo, foi proposto que cada mulher se virasse para a sua parceira à esquerda e dissesse a ela "eu preciso de você", recebendo a resposta "e eu estou aqui para te ajudar". O intuito dessa sensibilização foi retomar a história dessas mulheres, seus vínculos familiares, sua relação com aquele lugar e fazer com que elas reconhecessem na outra muito mais do que uma relação de parentesco ou de trabalho, mas uma relação de vínculo afetivo e de afinidade histórica de vida.

As místicas de sensibilização fazem parte dos caminhos utilizados pelas Metodologias Participativas que vêm atender às exigências da interdisciplinaridade e interprofissionalidade. A mística compõe as práticas pedagógicas e educativas do Movimento dos Trabalhadores Rurais Sem Terra (MST) - maior representação nacional de luta no campo - e envolve a espiritualidade com o intuito de fortalecer as lutas sociais (NASCIMENTO; MARTINS, 2008). As capacitações foram divididas em quatro módulos, totalizando 40 horas/aula, conforme metodologia estabelecida pela profissional contratada. Os encontros ocorreram nos finais de semana acordados entre elas, respeitando a interação dialógica a partir da compreensão da realidade do tempo daquelas mulheres. Previamente à capacitação, foram enviadas orientações que envolviam a necessidade de vestimentas, estrutura, materiais e matéria-prima adequados.

As mulheres organizaram um espaço na antiga escola da comunidade, já com banheiros, pia, tanque, água limpa e providenciaram a mudança da mesa, do fogão e do gás da cozinha comunitária para o ambiente Optou-se por não usar a cozinha comunitária com a intenção de criar um espaço de trabalho exclusivo das mulheres, onde elas pudessem guardar adequadamente o seu material de trabalho e se sentirem pertencentes e confortáveis nesse lugar. Foram utilizados os materiais e instrumentos de trabalho disponíveis nas cozinhas das casas das próprias agricultoras, os quais foram compartilhados com o grupo: panelas, liquidificador, faca, escumadeira, peneira, balde, copo, lixeira, pá de lixo, talheres, esponja, fósforo, pano de chão, papel toalha, avental, touca, tábua, vidros, hipoclorito de sódio 2 a 2,5\%, pincel atômico, conforme especificidades de cada item, atendendo aos padrões de higiene estabelecidos.

O levantamento da matéria-prima envolvia frutas, legumes e verduras produzidos na comunidade. Para aproveitar o período da capacitação e conhecer as diferentes formas de processamento para as diferentes variedades, algumas frutas foram adquiridas nos mercados convencionais já que a produção orgânica predominante na comunidade - depende da época de cada fruto. As frutas e hortaliças processadas foram banana, jabuticaba, berinjela, tomate, cenoura, maracujá, jurubeba, amora, pepino, manga e batata.

A capacitação envolveu as técnicas de higienização do local, dos utensílios, as orientações de vestimentas adequadas, além das técnicas de produção e de comercialização, incluindo a apresentação e precificação dos produtos. O encerramento desse espaço de formação foi realizado no dia 07 de outubro de 2017, momento em que cada integrante recebeu das mãos da facilitadora, o certificado produzido pelo Núcleo Travessia. A facilitadora também apontou as qualidades e habilidades de cada mulher e a importância de cada uma delas para a formação e fortalecimento do grupo. $\mathrm{O}$ resultado, em termos da produção dos doces, geleias e compotas, foi exposto durante o encerramento e pode ser visualizado na Figura 2.

Figura 2: Apresentação da produção de doces e conservas das mulheres da Peroba, Itajubá-MG.

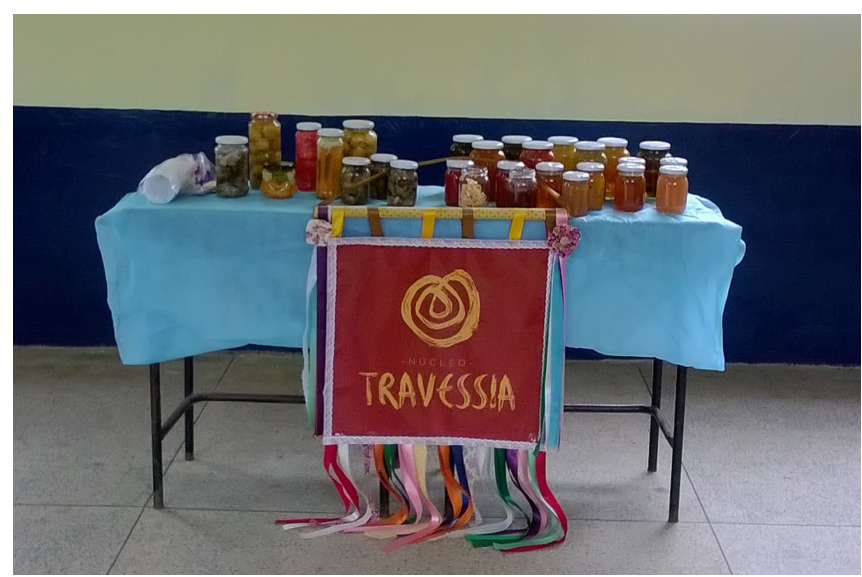

Figura 2: Apresentação da produção de doces e conservas das mulheres da Peroba, ttajubá-MG. 
O encontro permitiu uma avaliação, ainda que superficial, do trabalho realizado, registrado em formulário de avaliação. A ausência do Travessia durante as oficinas de capacitação impossibilitou uma avaliação nas diversas frentes: comunidade, mediação e Universidade. Entretanto, a continuidade do projeto mostrou que a relação de confiança está sendo construída progressivamente.

As inseguranças do grupo ficaram por conta do afastamento da mediadora com o encerramento das oficinas. As dificuldades que encontrarão, quando ela não estiver mais presente, e a necessidade de retorno para esclarecer as dúvidas que surgirem nesse período foram apontadas pelas mulheres. Além disso, há insegurança do grupo quanto à comercialização, apesar de já estarem desenvolvendo estratégias de venda, como a participação na FACI e a venda porta-emporta.

Os benefícios firmaram-se na expectativa de geração de renda e libertação da necessidade de realização de trabalho doméstico na cidade, na oportunidade das mulheres se encontrarem, conversarem e compartilharem suas experiências nesse espaço, na possibilidade de participação das jovens da comunidade e do aproveitamento de suas habilidades na elaboração dos custos e preços dos produtos, na possibilidade de usar o conhecimento nas receitas para a família, na percepção coletiva da necessidade de organização do grupo. Uma das mulheres relatou que "foi a primeira vez que alguém olhou pra gente" referindo-se ao interesse da Universidade e dos agentes de desenvolvimento de oferecer às mulheres da comunidade algo que atendesse às solicitações vindas delas e mantendo o apoio mesmo após finalizado o projeto.

Destaca-se a importância da entrega do certificado. Considerando o baixo grau de escolaridade dos agricultores e agricultoras e das dificuldades e preconceitos que enfrentam, cotidianamente, principalmente no contato com os estabelecimentos da cidade, a entrega do certificado equivaleu à comprovação física de uma formação próxima à escolar. Outra agricultora disse: - "Agora não vão mais poder dizer que eu não tenho diploma", informando que, apesar de já terem feito outros cursos de capacitação na comunidade, foi a primeira vez que elas receberam um comprovante de validação e confirmação dessa formação.

O impacto e a transformação social já começaram a dar sinais à medida que essas mulheres veem suas demandas atendidas, ainda que parcialmente, e percebem a materialização dos resultados do seu trabalho, reconhecido e valorizado pela comunidade. Outros pontos abordados na avaliação foi a habilidade da facilitadora em comunicar-se adequadamente com as mulheres. Ressalta-se que durante as oficinas, a profissional hospedou-se e alimentou-se na casa de uma agricultora aposentada. Essa aproximação estreita os laços de afeto e confiança e facilita a interação dialógica entre a profissional e a comunidade, mostrando a importância das competências necessárias para a realização desse tipo de trabalho.

Outras demandas futuras apresentadas pelo grupo de mulheres envolveram a necessidade de apoio: nos primeiros espaços de comercialização, na divulgação do trabalho, na consolidação da imagem do grupo e na aquisição de equipamentos para melhorar a infraestrutura de trabalho (armário de aço e fogão industrial).

\section{Organização coletiva e formação de grupo}

Para fomentar a organização coletiva e formação do grupo, foram realizadas outras cinco atividades como: (1) a participação no $1^{\circ}$ Encontro de Mulheres e Sistemas Participativos de Garantia (SPG's) da Região Sudeste em Inconfidentes; (2) Encontro sobre Economia Solidária realizada pelo Núcleo Travessia; (3) no XIV ENEDS - Encontro Nacional de Engenharia e Desenvolvimento Social realizado na UNIFEI; (4) Intercâmbio de Saberes em Campo do Meio; (5) e realização do encontro de encerramento do projeto e confraternização na própria comunidade. Todos os espaços organizados atendem, ainda que não em sua plenitude, as diretrizes do PNEU. Atores de diversos lugares sociais: pesquisadores, extensionistas, agentes de desenvolvimento, lideranças comunitárias, organizações não governamentais, coletivos, movimentos de base, estiveram presentes nesses espaços, de modo a possibilitar o diálogo diverso, interdisciplinar, interprofissional para a formação das diversas comunidades que compõem a sociedade, com vista a contribuir para o desenvolvimento local e a efetiva transformação social.

\section{Encontro de Mulheres e SPG's da Região Sudeste}

A convite de uma agricultora de Pedralva, as mulheres da Peroba puderam participar do $1^{\circ}$ Encontro de Mulheres e SPG's da Região Sudeste realizado nos dias 07 e 08 de junho de 2017, no município de Inconfidentes (MG). $\mathrm{O}$ encontro teve como objetivo discutir a garantia da participação das mulheres nos processos certificativos, o protagonismo feminino e sua importância para a agroecologia. Nos últimos anos, a pauta feminina está na centralidade dos debates acerca da agroecologia. As organizações de eventos têm exigido paridade nas inscrições e as entidades de certificação participativa vêm fomentando a isonomia entre coordenações (FERREIRA; MATTOS, 2017). Com o intuito de aproximar as mulheres da Peroba dessas discussões e incentivar a participação no processo de certificação ${ }^{4}$, o Núcleo Travessia subsidiou a participação de duas mulheres da Peroba 
no encontro em Inconfidentes.

Segundo Lima e Jesus (2017), a agroecologia propõe uma aliança progressista tanto do ponto de vista das questões ambientais, quanto da pluralidade cultural e da busca por uma sociedade melhor. No entanto, as autoras descreveram que para sua efetivação, a reprodução da desigualdade de gênero precisa ser superada, já que não existe agroecologia sem a valorização do trabalho feminino, pois a mulher é considerada central nesse processo (LIMA; JESUS, 2017).

As agricultoras que participaram do encontro disseram que foi importante ouvir histórias de vida de outras mulheres, que sofreram violências físicas e emocionais de seus maridos e família, mas que apesar disso, encontraram um caminho para a libertação e emancipação a partir do contato com outras mulheres e com espaços de trocas, capacitação, formação, dentro dos princípios da agroecologia. A interação dialógica não somente entre Universidade e Comunidade, mas entre grupos semelhantes, como as mulheres rurais, amplia o espectro de caminhos possíveis para superar as dificuldades encontradas nesses espaços. Conhecer outras realidades é um percurso para a conquista de uma efetiva transformação social.

\section{Encontro sobre Economia Solidária}

Para fortalecer a reflexão sobre a importância dos espaços coletivos de trocas e solidariedade, foi realizado um encontro sobre economia solidária na própria comunidade, em junho de 2017, facilitado pelos membros do Núcleo Travessia. A proposta pretendia reunir grupos de homens, jovens e mulheres para, a partir da execução da atividade proposta para cada grupo, refletir sobre o trabalho coletivo e a solidariedade, questionando sobre: por que trabalhar coletivamente? Por que ajudar o outro? Quais os benefícios dessa forma de trabalho?

O Fórum Brasileiro de Economia Solidária (FBES) definiu, de maneira geral, os seguintes princípios da economia solidária: a valorização social do trabalho humano; a satisfação plena das necessidades de todos como eixo da criatividade tecnológica e da atividade econômica; o reconhecimento do lugar fundamental da mulher e do feminino em uma economia fundada na solidariedade; a busca de uma relação de intercâmbio respeitoso com a natureza; e os valores da cooperação e da solidariedade (FBES, 2005). A aplicação desses princípios une todos os que produzem numa única classe de trabalhadores que são possuidores de capital por igual em cada cooperativa ou sociedade econômica. Através desses princípios, o resultado natural é a solidariedade e a igualdade (SINGER, 2002).

As desigualdades sociais atingem de forma diferente os homens e as mulheres (WILLIANS, 2014), pois as mulheres são sobrecarregadas com os trabalhos não remunerados, geralmente ligados às tarefas domésticas e aos cuidados dos filhos [...]. Ao mesmo tempo em que essas mulheres enfrentam problemas de inserção no mercado de trabalho, sofrem também com os rendimentos diferenciados dos homens com o mesmo nível de instrução (WILLIANS, 2014, p. 02).

A proposta do espaço para as mulheres referiase à valorização do preparo da comida. Durante o preparo da refeição, que deveria atender a toda a comunidade, seriam estabelecidos diálogos que permitissem conhecer a produção da comunidade e as expectativas quanto às oficinas de capacitação que estavam para iniciar, além de realizar a filmagem e fotografia desse momento - que seria realizado pelos jovens - para apresentação no final do encontro. Essa diferença ficou evidente na execução e avaliação das propostas de espaços para os jovens, homens e mulheres. A concepção do espaço das mulheres durante o preparo do almoço como um momento de diálogo não foi bem-sucedida. Enquanto os homens e os jovens conseguiram executar a atividade proposta para os seus espaços - preparo de adubo orgânico e filmagem e registro fotográfico, respectivamente - de forma prazerosa, estabelecendo diálogos, sem pressão, sem tensões, o espaço das mulheres permitiu poucas trocas e possibilidades de reflexão sobre o trabalho coletivo e solidário.

A organização do almoço coletivo é um trabalho difícil, que demanda muita atenção, uma vez que poucas são as mulheres que dominam esse tipo de espaço, fazendo com que o trabalho acabe concentrado nas mãos de quatro ou cinco. $O$ prazo para finalização do almoço também foi uma pressão sobre elas, que perceberam a tensão existente enquanto a refeição não saía.

A presença dos membros do Núcleo Travessia naquele espaço mais atrapalhou do que ajudou, pois, além de fazerem o que precisavam fazer, precisavam dar direcionamentos sobre o trabalho do outro. Entretanto, a filmagem e registro fotográfico desse momento foi assertivo. Apesar da agitação causada pela euforia das crianças e adolescentes no momento do registro, (o que conturbou o trabalho das cozinheiras) o resultado apresentado no encerramento do encontro foi positivo. As mulheres puderam ver o resultado de seu trabalho no vídeo elaborado pelos jovens. Segundo relatos de uma delas, vê-la no vídeo deixou-a emocionada e fez com que ela se sentisse importante.

A reflexão e avaliação foi um dos momentos mais importantes enquanto formação do estudante. Além da oportunidade de organizar as atividades, que envolveu o planejamento da proposta e a divisão das responsabilidades, essa ocasião favoreceu a troca de saberes em diversos aspectos. O maior aprendizado referiu-se ao espaço que NÃO deu certo. Apesar do planejamento e organização da atividade proposta para as mulheres, de conversas anteriores ao encontro com as mulheres da comunidade, os resultados pretendidos não foram alcançados. Essa experiência mostrou que, 
apesar das técnicas de gerenciamento e da racionalidade dos processos de planejamento, organização, direção e controle, há variáveis impossíveis de serem previstas. Ainda que o tempo tenha sido calculado, as tarefas divididas, as responsabilidades estabelecidas, havia configurações existentes no grupo que organiza e gerencia a cozinha comunitária que fugia ao conhecimento do Núcleo Travessia. As mulheres, para poder realizar o almoço coletivo, precisavam antes organizar as suas casas e a rotina de suas famílias, o que tornou o tempo um fator para além do controle do grupo.

A partir dessa experiência e reflexão, decidiu-se que os encontros futuros aconteceriam na parte da tarde, sem a necessidade do preparo de almoço coletivo, para que não sobrecarregassem ainda mais as mulheres da comunidade, fazendo com que elas também pudessem aproveitar, prazerosamente, as atividades propostas.

\section{Encontro Nacional de Engenharia e Desenvolvimento Social}

Além do preconceito de gênero e a carência de infraestrutura, o acesso aos mercados está entre os principais problemas dos grupos femininos que desempenham atividades alternativas, com o intuito de aumentar a renda familiar (SOUZA et al., 2016), problema compartilhado pelos agricultores $\mathrm{e}$ agricultoras familiares quando à comercialização da produção. Isso nos mostra a importância de ocupar os diversos espaços disponíveis e disponibilizados para expor, divulgar e comercializar a produção familiar. A primeira exposição e comercialização da produção das mulheres da Peroba ocorreu no XIV ENEDS, realizado na UNIFEI, em novembro de 2017. Elas foram convidadas, por intermédio do Núcleo Travessia, para participar da feira que ocorreria durante todos os 04 dias do evento.

$\mathrm{O}$ convite foi realizado pessoalmente às mulheres, no encontro de encerramento da oficina de capacitação. O Núcleo Travessia ofereceu apoio para ajudar na comercialização nos dias do encontro. Uma agricultora, juntamente com duas adolescentes da comunidade se organizaram e estiveram presentes expondo seus produtos. No relato da agricultora que assumiu essa responsabilidade, disse que estava muito insegura, mas que fez suas preces e pediu força para enfrentar seus medos. Foram comercializados os doces, compotas e conservas produzidos durante a oficina de capacitação. Foi vendida quase toda a produção, gerando os primeiros rendimentos para as mulheres, mostrando os primeiros impactos de transformação social.

A geração de renda para as mulheres, a partir do processamento do que se planta e colhe é também uma possibilidade de permanência no campo (SILVA; NASCIMENTO; GORES, 2015). Uma das mulheres da Peroba que trabalha como diarista disse que com a renda advinda da produção, ela poderá deixar o trabalho de faxina na cidade e dedicar-se ao trabalho com o grupo.

Além da geração de renda, o ENEDS foi uma oportunidade para as mulheres agricultoras ocuparem esse espaço dentro da Universidade, de apresentar o resultado de seu trabalho e iniciar os caminhos na organização para a comercialização. A agricultora relatou a experiência permitiu que ela percebesse demandas inerentes à comercialização, como por exemplo, a necessidade de troco. Também foi uma circunstância importante para a presença das adolescentes dentro da Universidade, tendo contato com outros jovens e podendo compartilhar suas experiências, além de aproveitar as suas habilidades para esse trabalho.

\section{Intercâmbio de saberes em Campo do Meio}

O Intercâmbio de Saberes aconteceu nos dias 09 e 10 de dezembro e teve por objetivo proporcionar o contato e a troca de experiência com o coletivo de mulheres "Raízes da Terra", grupo constituído no Assentamento Nova Conquista, em Campo do Meio (MG). O grupo de mulheres da Peroba, as mulheres do Núcleo Travessia e outras parceiras do grupo interessadas pela temática visitaram o assentamento e conheceram o trabalho desenvolvido por esse coletivo, que existe há mais de cinco anos, como pode ser visto na Figura 3.

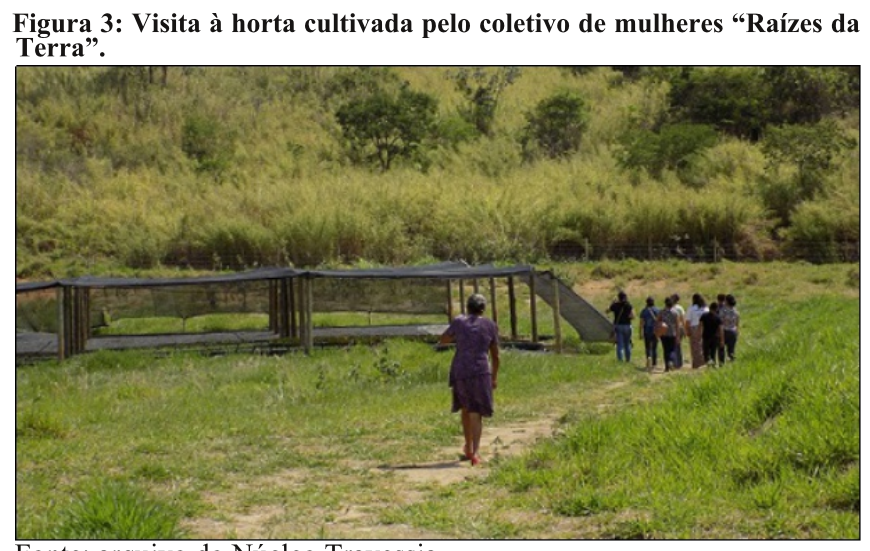

Fonte: arquivo do Núcleo Travessia.

Atualmente, o "Raízes da Terra" possui uma área de produção coletiva com horta medicinal orgânica de onde elas tiram as ervas para produzir fitoterápicos. As mulheres do coletivo receberam as visitantes com um café com quitandas, mandioca, suco e frutas. Durante o encontro houve muita empatia entre as mulheres dos grupos, numa atmosfera de trocas de experiências e solidariedade. $O$ encerramento foi marcado por um momento místico onde todas se debruçaram em lágrimas.

As mulheres do coletivo organizaram uma roda 
de lava-pés, duas delas, uma com uma bacia com água e ervas aromáticas tranquilizantes e outra com a toalha, passaram molhando, massageando e secando os pés de todas as mulheres da roda, representando um gesto de cuidado e carinho. O coletivo compartilhou, ainda, as dificuldades que sofreu ao longo dos anos, mostrando a importância do trabalho coletivo na superação dos desafios. As mulheres da Peroba demonstraram muita gratidão pela experiência e ficaram admiradas com o trabalho que o "Raízes da Terra" faz, sentindo-se fortalecidas para continuarem caminhando com o grupo que estão formando.

\section{Encerramento do projeto e confraternização na comunidade}

Nos primeiros encontros na comunidade, no levantamento das demandas, uma das questões latentes foi a ausência de lazer, principalmente para os jovens e as mulheres. Durante todo o ano de execução do projeto, as moradoras e moradores da Peroba convidaram o Núcleo Travessia para um dia festivo, onde fosse possível confraternizar, por meio de brincadeiras e músicas. Diante disso, a proposta de um encontro com gincana, roda de música e a celebração da missa teve a intenção de entreter a comunidade, celebrar os resultados colhidos através do projeto de extensão e apresentar os vídeos sobre a comunidade elaborados pelo Núcleo Travessia.

O evento aconteceu nos dias 09 e 10 de dezembro, data escolhida pela comunidade. No primeiro dia, os moradores da Peroba organizaram uma gincana com várias brincadeiras, como corrida de saco, cabo de guerra, dança das cadeiras, corrida das vassouras, corrida da laranja, entre outras. A competição foi dividida entre grupo dos meninos e grupo das meninas. No domingo, dia 10 , comunidade e Núcleo Travessia participaram de uma missa, celebrada para agradecer essa parceria. O tema da homilia tratou da transformação por meio de ações coletivas e solidárias, reforçando a união na comunidade. Após a missa, foram apresentados dois vídeos, elaborados pelo Núcleo Travessia a partir dos registros feitos pelos jovens da comunidade no encontro de junho de 2017.

No encerramento, as mulheres que participaram do projeto leram um poema escolhido por elas e entregaram lembrancinhas para todos os membros do Núcleo Travessia como forma de agradecimento pelo apoio dado à comunidade. Pôde-se observar que a comunidade trabalhou coletivamente para organização do encontro e que as mulheres se organizaram para pensar o momento final de agradecimento. Além disso, as mulheres começam a dar sinais de organização para a produção e comercialização autônoma, despertando para a ação coletiva e independente, o que pode significar uma melhoria da autoestima e da confiança de que são capazes de desempenhar atividades importantes para a comunidade, para suas famílias e para elas mesmas.

O encerramento foi marcado pela interação dialógica e o estreitamento dos laços entre a Universidade e a Comunidade, consolidando a relação de confiança tão importante para o sucesso de projetos de extensão. Verificou-se a importância das parcerias entre comunidades rurais e instituições de ensino, onde a realização de cursos e capacitações têm sido o ponto de partida para muitas organizações de mulheres rurais. Esses grupos, em primeiro momento, têm o objetivo pontual de produzir e gerar renda, mas com o tempo promovem múltiplas transformações sobre o papel da mulher no meio rural.

\section{Considerações finais}

As mulheres vivem, historicamente, em condições subalternas ao homem e no meio rural isso se torna ainda mais evidente, uma vez que o trabalho da mulher é, muitas vezes, invisibilizado, sem reconhecimento e sem renda direta, pois está relacionado aos cuidados de casa e na ajuda ao companheiro. Projetos que sejam capazes de incentivar a geração de renda das mulheres rurais, valorizar seus trabalhos e promover a autonomia socioeconômica são fundamentais para alterar esse quadro social.

Por meio da discussão dos caminhos percorridos pelo Núcleo Travessia na elaboração e execução do projeto de extensão "Economia Solidária na Peroba Itajubá-MG: geração de renda e emancipação social das mulheres rurais", verificou-se que a interação dialógica foi fundamental para estabelecer relação de confiança e equidade entre Universidade e Comunidade. Da aproximação com a comunidade, na elaboração do projeto, a partir dos resultados de pesquisa participativa, até o encontro de encerramento, o diálogo $\mathrm{e}$ o respeito aos saberes locais foi estabelecido, respeitando a interdisciplinaridade e a interprofissionalidade.

As dificuldades ficaram por conta do tempo de aproximação e de realização do projeto, considerando ser o primeiro ano de efetivação de atividades extensionistas na comunidade. Juntou-se a isso o fator tempo de dedicação, já que a Universidade na qual o Núcleo Travessia está inserido ainda não fez valer os $10 \%$ do total de créditos exigidos para a graduação no ensino superior no país, reservados para a atuação dos alunos em ações extensionistas (FORPROEX, 2012). Isso fez e faz com que os membros do Travessia tenham que se organizar para incluir as diversas atividades do núcleo na sua rotina estudantil, o que inclui trabalhos em finais de semana e feriados, além de predominantemente voluntário, haja vista o limite de recursos.

As conquistas superaram as dificuldades - mas não as neutralizam fazendo necessária a atuação junto à Universidade pela efetivação da meta estabelecida - 
e dão fôlego e motivação continuar a atuar com a comunidade. A aproximação de profissionais de diferentes formações e com habilidades para trabalhar de forma competente fez com que o Núcleo Travessia e a comunidade ampliassem as parcerias, fundamentais em projetos dessa natureza. Tendo como pilar fundamental desde a sua formação a indissociabilidade ensino-pesquisa-extensão e a preocupação com a formação cidadã dos estudantes, o Núcleo Travessia formou e está formando alunos conscientes de seu papel e de sua responsabilidade diante do seu privilégio de formação universitária pública.

Todas as pesquisas desenvolvidas pelo grupo visavam e visam a troca, a participação da comunidade pesquisada, a formação político-cidadã dos alunos e da comunidade e a devolutiva dos resultados, preferencialmente e, principalmente, na materialização desses resultados em ações e projetos de extensão que proponham atender reinvindicações da comunidade. Ainda que singelos e iniciais, o projeto de capacitação das mulheres do bairro rural da Peroba já propiciou os primeiros rendimentos, além de uma expressiva melhoria na autoestima dessas mulheres. Além disso, criou oportunidade para elas e as jovens mulheres da comunidade participarem de outros espaços, estabelecendo trocas de conhecimento, de experiências e de vida rumo a uma efetiva transformação social.

\section{Referências}

CAMPOS, C. P. Mulheres rurais atuando no fortalecimento da agricultura familiar local. GENNERO, Niterói, v. 15, n. 1, p. 29-46, jul./dez. 2014.

FBES. Fórum Brasileiro de Economia Solidária. Carta de Princípios da Economia Solidária. 2005. Disponível em: $<$ http://fbes.org.br/2005/05/02/carta-de-principios-daeconomia-solidaria> Acesso em: 14 jan. 2018.

FERREIRA, A. P. L; MATTOS, L. C. Convergências e divergências entre feminismo e agroecologia. Revista Ciência e Cultura, São Paulo, v. 69, n. 2, p. 38-43, abr./jul. 2017.

FORPROEX. Fórum de Pró-reitores de Extensão das Universidades Públicas Brasileiras. Política Nacional de Extensão Universitária. 2012. Disponível em: $<$ http://proex.ufsc.br/files/2016/04/Política-Nacional-deExtensão-Universitária-e-book.pdf $>$. Acesso em: 23 jul. 2017.

FREIRE, P. Extensão ou Comunicação? 13. ed. São Paulo: Paz e Terra, 2006.

FREIRE, S. M. Desafios da Extensão Universitária na Contemporaneidade. Revista Conexão, Ponta Grossa, v. 07, p. 08-15, 2011.

GARCIA JR., A. R. O Sul: caminho do roçado. São Paulo: Marco Zero, 1989.

HEREDIA, B. M. A. A morada da vida: Trabalho familiar de pequenos produtores no Nordeste do Brasil. Rio de Janeiro: Paz e Terra, 1979.

IBGE. INSTITUTO BRASILEIRO DE GEOGRAFIA E ESTATISTICA. Censo Agropecuário 2006. Disponível em:

$<\mathrm{http} / / /$ www.ibge.gov.br/home/estatistica/economia/agropec uaria/censoagro/> Acesso em: 10 dez. 2017.

LANDINI, F. P. Problemas enfrentados por extensionistas rurais brasileiros e sua relação com suas concepcõ̃es de extensão rural. Ciência Rural, Santa Maria, v. 45. n. 2, p. 371-377, 2015

LIMA, E. M.; PEREIRA, S. B.; PEREIRA, V. G.; PEREIRA, M. S. Produção e comercialização no bairro rural da Peroba, em Itajubá (MG): entre potencialidades, demandas e expectativas. In.: SEMINARIO DE POLITICAS CULTURAIS E AMBIENTAIS, 2, 2017, Itajubá. Anais... Itajubá: UNIFEI, 2018 (no prelo).

LIMA, M. M. T.; JESUS, V. B. Questões sobre gênero e tecnologia na construção da agroecologia. Scienti e Studia, São Paulo, v. 15, n. 1, p. 73-96, 2017.

MÉLO, A. B.; MORAES, L. L.; COSTA, M. A. G. Grupo de Mulheres Rurais "Reciclarte": a fuga do cotidiano. In.: Encontro Nacional da REDOR, 18, 2014, Recife. Anais eletrônicos... Recife: UFRP, 2014, p. 3812-3821.

Disponível em:

<http://www.ufpb.br/evento/lti/ocs/index.php/18redor/18red or/paper/viewFile/1919/881> Acesso em: 10 dez. 2017.

MENASCHE, R.; BELEM, R. C. Gênero e agricultura familiar: trabalho e vida na produção de leite do sul do Brasil. Raízes, Campina Grande, v. 17, n. 17, p. 135-142, 1998.

MESQUITA, L. A. P.; MENDES, E. P. P. Mulheres na agricultura familiar: a comunidade Rancharia In: Encontro Nacional de Geografia Agrária, n. 21, 2012, Uberlândia. Anais eletrônicos... Uberlândia: UFU, 2012, p. 1-20. Disponível em:

$<$ http://www.lagea.ig.ufu.br/xx1enga/anais_enga_2012/eixo s/1104_1.pdf $>$ Acesso em: 05 dez. 2017.

MORAIS, J. A.; CALLOU, A. B. F. Metodologias participativas e desenvolvimento local: a experiência do Projeto Dom Hélder Câmara no assentamento Moacir Lucena. Revista Interações, Campo Grande, v. 18, n. 1, p. 165-177, jan./mar. 2017.

NASCIMENTO, C. G.; MARTINS, L. C. Pedagogia da mística: as experiências do MST. Revista Emancipação, Ponta Grossa, v. 8, n. 2, p. 109-120, 2008.

PEIXOTO, M. Marcos legais dos serviços precursores de ATER no Brasil. In: Congresso Brasileiro de Assistência Técnica e Extensão Rural ConbATER, 4, 2008, Londrina. Anais... Londrina: Associação dos Engenheiros Agrônomos de Londrina, 2008, p. 544-560.

PACHECO, M. E. L. Sistemas de Produção: Uma perspectiva de gênero. Revista Proposta, Rio de Janeiro, ano 25, n. 71, 1997.

PAULILO, M. I. S. O peso do trabalho leve. Ciência Hoje, Rio de Janeiro, v. 5, n. 28, p. 64-70, 1987.

PEREIRA, V. G., BRITO, T. P.; PEREIRA, S. B. A feiralivre como importante mercado para a agricultura familiar em Conceição do Mato Dentro (MG). Revista Ciências Humanas, Taubaté, v. 10, n. 2, p. 67-78, 2017.

RAMOS, C. P. Mulheres rurais atuando no fortalecimento da agricultura familiar local. Revista Gênero, Niterói, v. 15, n. 1, p. 29-46, jul./dez. 2014.

SARAIVA, L. A. S. Além dos estigmas profissionais. In: FREITAS, M. E; DANTAS, M. Diversidade sexual e trabalho. São Paulo: CENGAGE Learning, 2012, p. 149168.

SILVA, A. T. B.; NASCIMENTO, R. S.; GORES, J. Agroecologia, relações produtivas e de gênero na agricultura familiar: o estudo de caso da Associação de Produtores Agroecológicos Sementes do Futuro de Atalanta - SC. Ágora, Santa Cruz do Sul, v. 17, n. 02, p. 131-143, jul./dez. 2015. 
EXTENSÃO UNIVERSITÁRIA: UMA ANÁLISE DA CONSTRUÇÃO DE UM PROJ̦ETO DE EXTENSÃO COM AS MULHERES RURAIS DO BAIRRO PEROBA

SINGER, P. Introdução à Economia Solidária. São Paulo: Editora Fundação Perseu Abramo, 2002.

SOUZA, P. G.; CARVALHO, A. L.; SANINI, C.; SEABRA Jr., S.; LIMA, A. F. A.; BUTNARIU, A. R.; QUEIROZ, T. M.; FRANCA, R. N. C. Estudo das alternativas para a melhoria do empreendimento feminino: doces e conservas frutos do vale. Revista Conexão, Ponta Grossa, v. 12, n. 2, p. 279-291, 2016.

WILLIAMS, P. O empoderamento feminino e as mulheres do programa Bolsa Família. Revista Três Pontos, Belo Horizonte, v. 11, n. 1, p. 18-31, 2014.

ZUIN, L. F. S.; ZUIN, P. B.; MANRIQUE, M. A. D. A comunicação dialógica como fator determinante para os processos de ensino-aprendizagem que ocorrem na capacitação rural: um estudo de caso em um órgão público de extensão localizado no interior do Estado de São Paulo. Ciência Rural, Santa Maria, v. 41, n. 5, p. 917-923, 2011.

\section{Notas}

${ }^{1}$ Núcleo de Pesquisa, Extensão e Apoio à Agricultura Familiar e Desenvolvimento Rural. Os projetos de pesquisa e extensão desenvolvidos pelo grupo podem ser acessados em https://nucleotravessia.unifei.edu.br/

2 A aproximação e a visitação à comunidade compuseram os resultados do projeto de pesquisa "Expressividade socioeconômica da agricultura familiar para o desenvolvimento territorial em municípios do sul de Minas Gerais" registrado na Diretoria de Pesquisa e Inovação (DPI) da Universidade Federal de Itajubá, processo $\mathrm{n}^{\circ}$ 519, com financiamento interno. A síntese dos resultados alcançados com as primeiras visitas à Peroba está registrada no artigo "Produção e comercializacão no bairro rural da Peroba, em Itajubá (MG): entre potencialidades, demandas e expectativas", submetido para o II Seminário de Políticas Culturais e Ambientais e com previsão de publicação nos anais do encontro para 2018. Veja LIMA et al. (2018).

${ }^{3}$ Edital n ${ }^{\circ}$ 01/2017/UNIFEI/PROEX, de 16 de janeiro de 2017 (vigência 2017).

${ }^{4}$ Sete famílias da Peroba são certificadas como produtoras de orgânicos por meio da Organização de Controle Social (OCS). 